\title{
OPTIMIZATION TECHNIQUES FOR SOURCE FOLLOWER BASED TRACK-AND-HOLD CIRCUIT FOR HIGH SPEED WIRELESS COMMUNICATION
}

\author{
Manoj Kumar ${ }^{1}$ and Gagnesh Kumar ${ }^{2}$ \\ ${ }^{1}$ Department of Electronics \& Comm., Vidya College of Engg., Meerut (U.P) \\ Manoj.kr.nitegmail.com \\ ${ }^{2}$ Department of Electronics \& Comm., NIT Hamirpur, Hamirpur (H.P) \\ Gagnesh@nitham.ac.in
}

\begin{abstract}
Since the current demand for high-resolution and fast analog to digital converters (ADC) is driving the need for track and hold amplifiers $(T \& H)$ operating at RF frequencies. A very fast and linear T\&H circuit is the key element in any modern wideband data acquisition system. Applications like a cable-TV or a broad variety of different radio standards require high processing speeds with high resolution. The track-and-hold $(T \& H)$ circuit is a fundamental block for analog-to digital $(A / D)$ converters. Its use allows most dynamic errors of $A / D$ converters to be reduced, especially those showing up when using high frequency input signals. Having a wideband and precise acquisition system is a prerequisite for today's trend towards multi-standard flexible radios, with as much signal processing as possible in digital domain. This work investigates effect of various design schemes and circuit topology for trackand-hold circuit to achieve acceptable linearly, high slew rate, low power consumption and low noise.
\end{abstract}

\section{KEYWORDS}

Track and Hold Circuit, Low Power Consumption, Slew Rate, Peak Power, Sampling Switch, Flash Analog to Digital Converter

\section{INTRODUCTION}

Track and hold circuit is the fundamental block for analog to digital (A/D) converters. Track and hold circuit is inserted in front of a comparator array of a flash A/D converter to keep comparator's input voltages constant while the comparators are settling their output voltage levels. Track and hold architecture can be classified into two classes (fig.1): open-loop and closed-loop architecture [1]-[5].

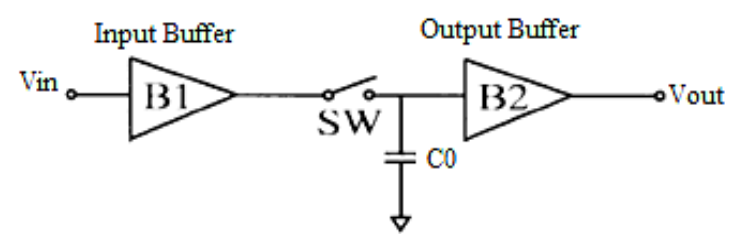

Figure 1a. Open-loop T/H

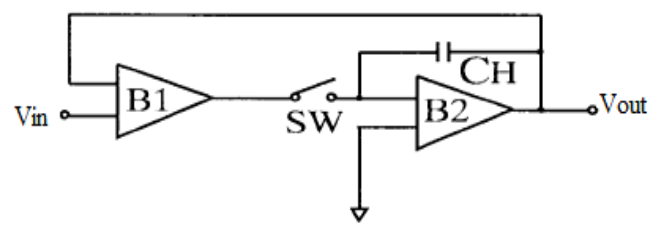

Figure 1b. Closed-loop T/H

The open loop T/H circuit is suitable for high precision but not for high speed. Most CMOS $\mathrm{T} / \mathrm{H}$ circuits proposed/implemented so far employ closed-loop architecture to obtain better than 8 bit accuracy. However closed loop architectures suffer from relatively lower sampling frequency and higher power consumption as compared to open-loop architecture [6]. Open- 
loop architectures tend to consume lower power and work at high sampling frequencies than closed-loop ones. Open-loop architectures have been used in high-speed ADCs [3][4].

Source-follower-based $\mathrm{T} / \mathrm{H}$ circuit has been optimized with respect to linearity, noise, and speed and power consumption.This paper investigates effect of various design schemes and circuit topology for track-and-hold circuit to achieve acceptable linearly, high slew rate, low power consumption and low noise. Superior speed \& acceptable linearity of source-followers makes it promising candidate for the purpose of this work.

\section{SAMPLING SWITCHES FOR T/H}

The sampling network consists of a sampling switch $\left(\mathrm{M}_{\mathrm{sw}}\right)$ and a hold capacitor $\left(\mathrm{C}_{\mathrm{s}}\right)$ to store the value of sampled signal during the hold mode. During the tracking phase, the combination of the switch and the capacitor forms a first-order RC network, the time-constant of which sets the maximum achievable sampling frequency. The speed of sampling network appears not to be a serious limitation in this work because as will be seen the chosen operating frequency is far less than the time-constant of the switch network and is basically limited by other parts of the circuit [15].

The noise contribution due to the sampling network is dependent on the sampling capacitance value and the width of the switching transistor. In addition to the noise added by the switch, the non-linearity due to the signal-dependent behaviour of the switch can degrade the overall linearity of the $\mathrm{T} / \mathrm{H}$ circuit.

\subsection{Single MOS Switch}

The maximum output voltage that an NMOS transistor can deliver is approximately equal to $\mathrm{V}_{\mathrm{dd}} \mathrm{V}_{\text {th. }}$

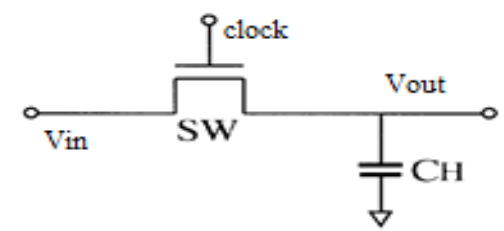

Figure 2. Single MOS sampling switch

The on-resistance of a long-channel MOS device operating in the linear (triode) regions is given by:

$$
R_{O N}=\frac{1}{\mu C_{O X} \frac{W}{L}\left(V_{g s}-V_{t h}\right)}
$$

From the above expression it is clear that the resistance of NMOS switch is non-linear that is approaches infinity when Vin approaches Vdd-Vth,which is the upper limit of the NMOS transistor [10].

\subsection{Transmission-Gate Switch}

To circumvent the above problem with a varying switch resistance the benefit of NMOS for low input voltages and the PMOS for high input voltages can be Utilized.it is done simply by connecting them in parallel and thereby forming a transmission gate. 


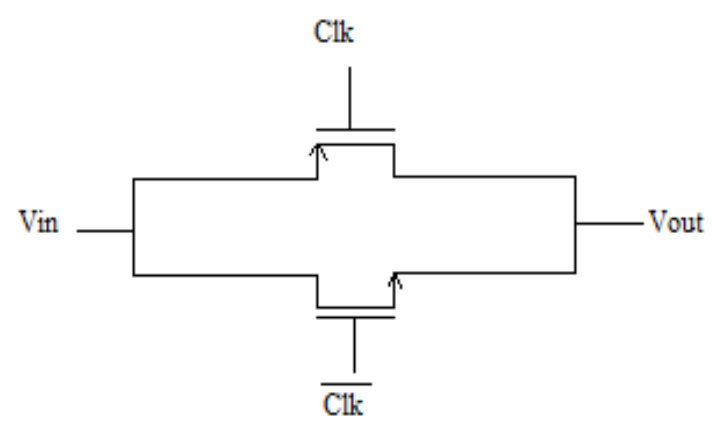

Figure 3. Transmission gate sampling switch

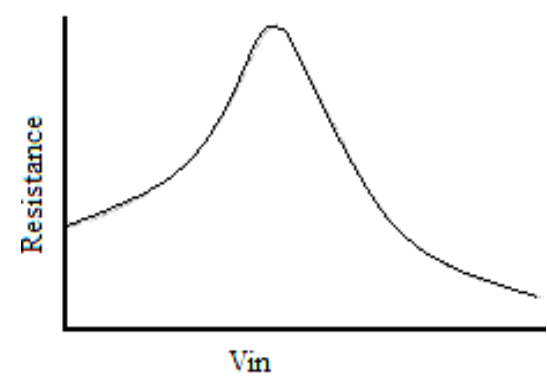

Figure 4. On-resistance of the transmission gate

NMOS transistor shows the non-linear characterisitcs for high voltages. This is why NMOS transistor works poorly for high voltages. A PMOS transistor on the other hand, is known to work poorly for low voltages and rather for high voltages.

The transmission-gate-switch ( NMOS-and-PMOS transistor connected in parallel ) might be the solution to the problem faced by single NMOS and PMOS switches. As seen in figure, the resistance for the transmission-gate-switch is much linear that is why transmission-gateswitches can be wise choice to get acceptable linearty and large output gain [18].

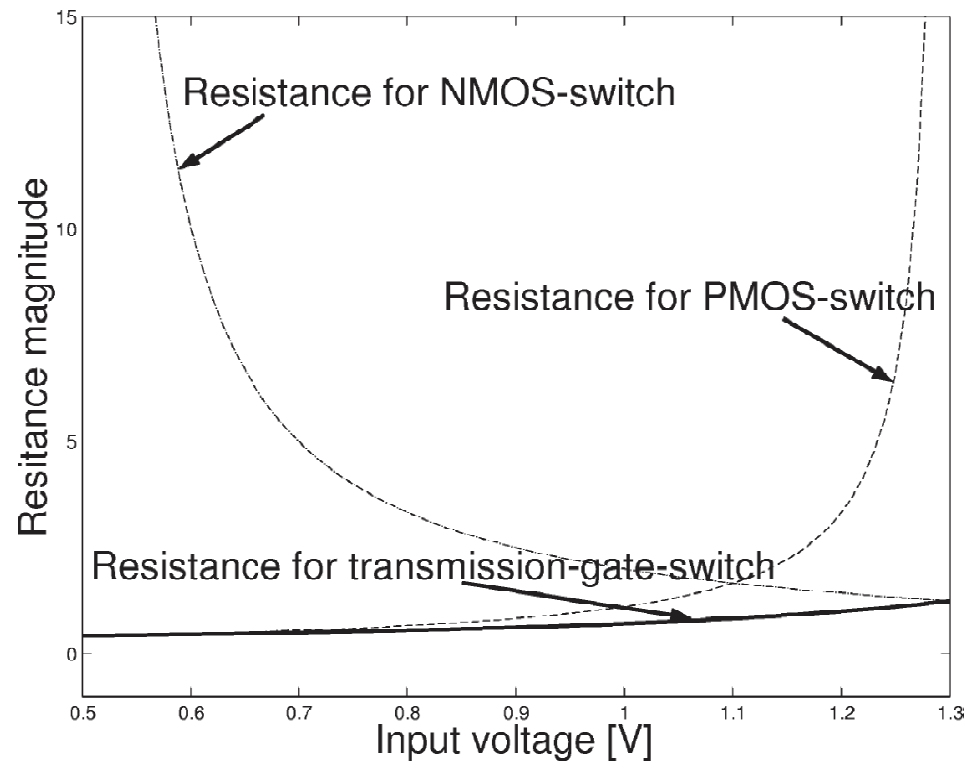

Figure 5. Resistance magnitude of sampling switches

\section{CONVENTIONAL T/H USING SOURCE FOLLOWER}

Source follower was used in this work to drive the load capacitance of the T/H stage. The active devices in the source-follower contribute to the noise in both the track and hold modes of 
operation. The noise of these devices mainly due consists of channel thermal noise and gate flicker noise.

\subsection{Analysis of T/H Circuit Using NMOS Sampling Switch}

A conventional source follower $\mathrm{T} / \mathrm{H}$ circuit basically consists of input, output buffers, a switch and a sampling capacitor. An output buffer is usually used to charge and discharge the input capacitances of following comparators.

A T/H circuit has two operation phases named "track phase" and "hold phase". During a track phase the switch is shorted and $\mathrm{V}_{\text {out }}$ becomes equal to $\mathrm{V}_{\text {in. }}$. On the other hand, during a hold phase the switch is opened and the T/H circuit keeps its output voltage equal to the value at end of track phase. A required hold time of a T/H circuit is usually decided by a settling time of the following comparators since the comparators must settle their output voltage during a hold time [9].

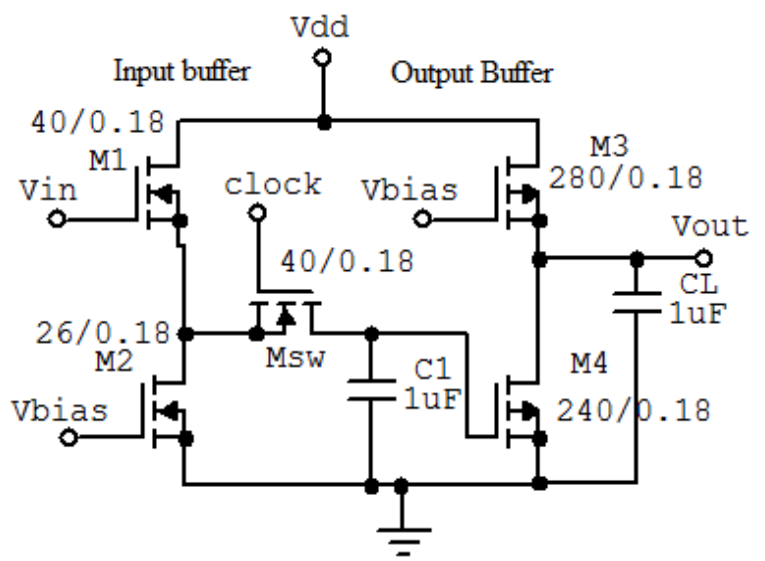

Table 1. Design specification of $\mathrm{T} / \mathrm{H}$

Figure 6. Single ended conventional T/H

\begin{tabular}{|l|l|}
\hline Power supply voltage & \multicolumn{1}{|c|}{$1.8 \mathrm{v}$} \\
\hline $\begin{array}{l}\text { Maximum input signal } \\
\text { frequency }\end{array}$ & $500 \mathrm{MHz}$ \\
\hline Sampling frequency & $1 \mathrm{GHz}$ \\
\hline $\begin{array}{l}\text { Maximum output voltage } \\
\text { swing (Ain) }\end{array}$ & $1 \mathrm{Vp}-\mathrm{p}$ \\
\hline Resolution & $6 \mathrm{bit}$ \\
\hline Load capacitance $\left(\mathrm{C}_{\mathrm{L}}\right)$ & $10 \mathrm{pf}$ \\
\hline Input offset & $0.8 \mathrm{v}$ \\
\hline CMOS technology & $0.18 \mu \mathrm{m}$ \\
\hline
\end{tabular}

An input voltage represented by

$$
V_{\text {in }}=A_{\text {in }} \sin \left(\omega_{\text {in }}+\varphi_{\text {in }}\right)
$$

Where $A_{\text {in }}$ is equal to the maximum input voltage given by the specifications and $\omega_{\text {in }}$ is set to $2 \pi$ $\left(f_{s} / 2\right) . f_{s}$ means its sampling frequency.

\subsection{Analytical Modeling of Conventional T/H Circuit}

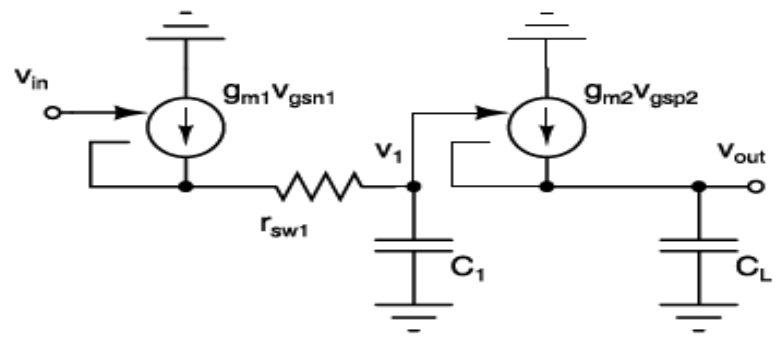

Figure 7. Small signal model of conventional T/H 
A Transfer functions from $V_{\text {in }}$ to $V_{1}$, and from $V_{1}$ to $V_{\text {out }}$ is represented by

$$
\begin{aligned}
T_{1}(s)=\frac{v_{1}}{v_{\text {in }}}=\frac{1}{1+s C_{1}\left(\frac{1}{g_{m 1}}+r_{s w 1}\right)} & & T_{2}(s)=\frac{v_{\text {out }}}{v_{1}}=\frac{1}{1+s C_{L}\left(\frac{1}{g_{m 2}}\right)} \\
=\frac{1}{1+s \tau_{1}} & (3) & =\frac{1}{1+s \tau_{2}}
\end{aligned}
$$

Respectively, where $\tau_{1}$ and $\tau_{2}$ is time constant which is defined by

$$
\begin{gathered}
\tau_{1}=C_{1}\left(\frac{1}{g_{m 1}}+r_{S w 1}\right), \\
\tau_{2}=\frac{C_{L}}{g_{m_{2}}}
\end{gathered}
$$

$$
\begin{aligned}
g_{m_{2}} & =\frac{C_{L}}{\tau_{2}}, \frac{1}{g_{m 1}}=\frac{\sqrt{\alpha_{n}}}{\sqrt{\alpha_{n}}+\sqrt{\beta_{n}}} \frac{\tau_{1}}{C_{1}}, \\
\mathrm{r}_{\mathrm{sw} 1} & =\frac{\sqrt{\beta_{\mathrm{n}}}}{\sqrt{\alpha_{\mathrm{n}}}+\sqrt{\beta_{\mathrm{n}}}} \frac{\tau_{1}}{C_{1}}
\end{aligned}
$$

Where $\alpha_{n}, \beta_{n}$ is defined as follows

$\alpha_{n}=\frac{\left(V_{g s}-V_{T_{n}}\right) g_{m 1}}{2}, \quad \beta_{n}=\frac{L_{s w 1}^{2} f_{s} V_{d d}}{\mu_{n}\left(V_{g s}-V_{t n}\right)} \frac{1}{r_{s w 1}}$

On the assumption that an acceptable gain error at the input buffer of the $\mathrm{T} / \mathrm{H}$ circuit is $\mathrm{e}_{1}$ an optimum $\tau_{1}$ must satisfy

$$
\left|\mathrm{T}_{1}\left(\mathrm{j} \omega_{\max }\right)\right|=\frac{1}{\sqrt{1+\omega_{\max }^{2} \tau_{1} 2}}=1-\mathrm{e}_{1} \quad \text { (8) } \quad \text { and } \mathrm{v}_{\text {out }}(\mathrm{t})=\mathrm{L}^{-1}\left[\frac{1}{1+\mathrm{s} \tau_{2}} \cdot \mathrm{V}_{1}(\mathrm{~s})\right]
$$

Where $\mathrm{V}_{1}(\mathrm{~s})$ is the output of the input buffer of conventional $\mathrm{T} / \mathrm{H}$ circuit.

Table 2. Hspice smulation of conventional $\mathrm{T} / \mathrm{H}$ circuit

\begin{tabular}{|l|l|}
\hline Vout & $1.46 \mathrm{v}$ \\
\hline $\begin{array}{l}\text { Average power } \\
\text { consumption }\end{array}$ & $76.94 \mathrm{mw}$ \\
\hline $\begin{array}{l}\text { peak power over } \\
\text { a cycle }\end{array}$ & $89.08 \mathrm{mw}$ \\
\hline Slew rate & $89.64 \mathrm{mv} / \mathrm{ns}$ \\
\hline Track time & $0.92 \mathrm{~ns}$ \\
\hline Hold time & $0.76 \mathrm{~ns}$ \\
\hline
\end{tabular}

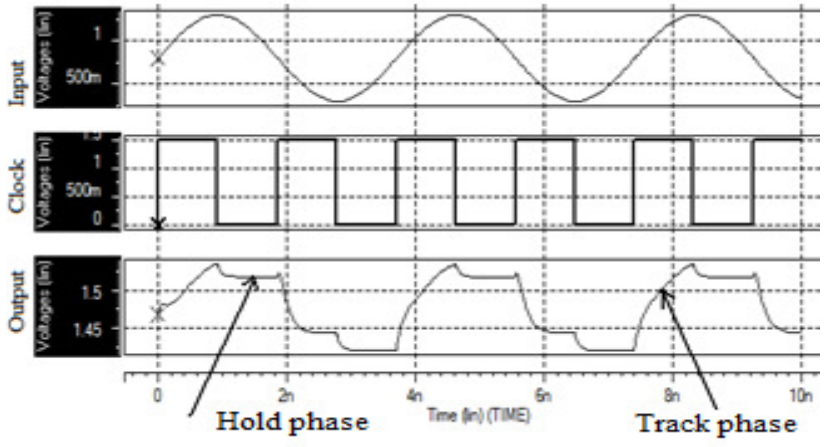

Figure 8. Output waveform for conventional $\mathrm{T} / \mathrm{H}$ 


\subsubsection{Noise Analysis of Conventional T/H Circuit}

Table 2. Noise results of conventional

\begin{tabular}{|l|l|}
\multicolumn{3}{|c}{$\mathrm{T} / \mathrm{H}$} \\
\hline $\begin{array}{l}\text { Total output noise } \\
\text { voltage }\end{array}$ & $\begin{array}{l}6.945 \mathrm{e}-01 \quad \mathrm{Sq} \\
\text { V/Hz=833.37p } \\
\text { V/Rt(Hz) }\end{array}$ \\
\hline $\begin{array}{l}\text { Transfer function } \\
\text { value (Vout/Vin ) }\end{array}$ & $1.64882 \mathrm{n}$ \\
\hline $\begin{array}{l}\text { Equivalent input } \\
\text { noise at Vin }\end{array}$ & $505.43604 \mathrm{~m}$ \\
\hline $\begin{array}{l}\text { Total equivalent } \\
\text { input noise voltage }\end{array}$ & $1.14265 \mathrm{~K} \mathrm{~V}$ \\
\hline
\end{tabular}

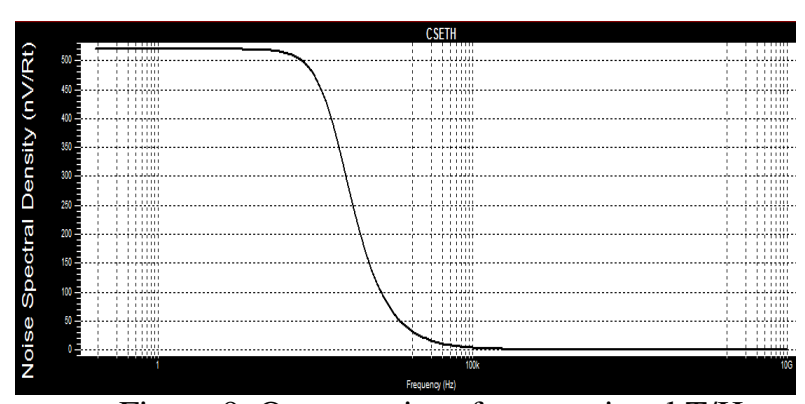

Figure 9. Output noise of conventional T/H

\subsection{Analysis of T/H Circuit using Transmission-Gate Sampling Switch}

Here NMOS sampling switch is replaced with Transmission-gate sampling switch. As discussed earlier that On-resistance of Transmission-gate shows the linear characteristics hence linearity in output waveform is expected this is confirmed by the HSPICE simulation result. It improves the linearity but at the cost of area overhead. We require one more clock to use transmissiongate sampling switch

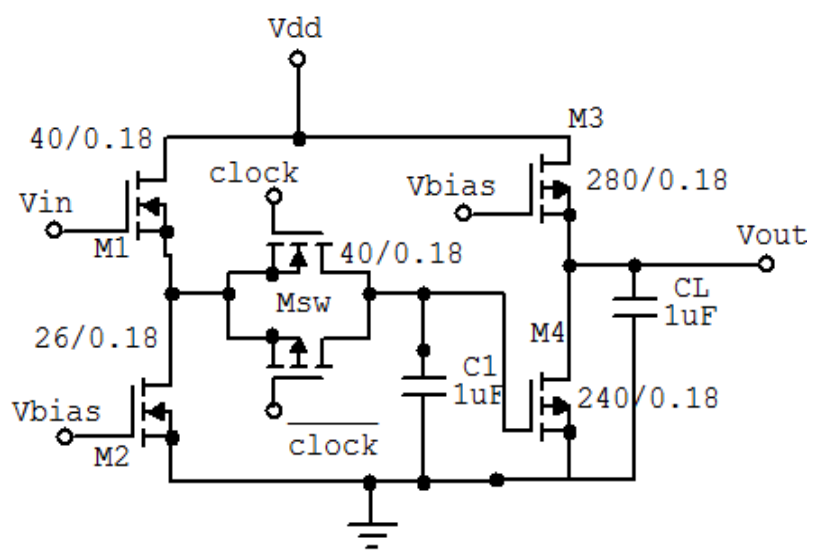

Table 3. Hspice simulation results for conventional Track-and-Hold using Transmission-Gate

\begin{tabular}{|l|l|}
\hline $\mathrm{V}_{\text {out }}$ & $1.57 \mathrm{v}$ \\
\hline $\begin{array}{l}\text { Average power } \\
\text { consumption }\end{array}$ & $78.33 \mathrm{mw}$ \\
\hline $\begin{array}{l}\text { Peak power over } \\
\text { a cycle }\end{array}$ & $90.91 \mathrm{mw}$ \\
\hline Slew rate & $110.48 \mathrm{mv} / \mathrm{ns}$ \\
\hline Track time & $0.92 \mathrm{~ns}$ \\
\hline Hold time & $0.81 \mathrm{~ns}$ \\
\hline
\end{tabular}

Figure 10. Conventional T/H using Transmission-gate sampling switch

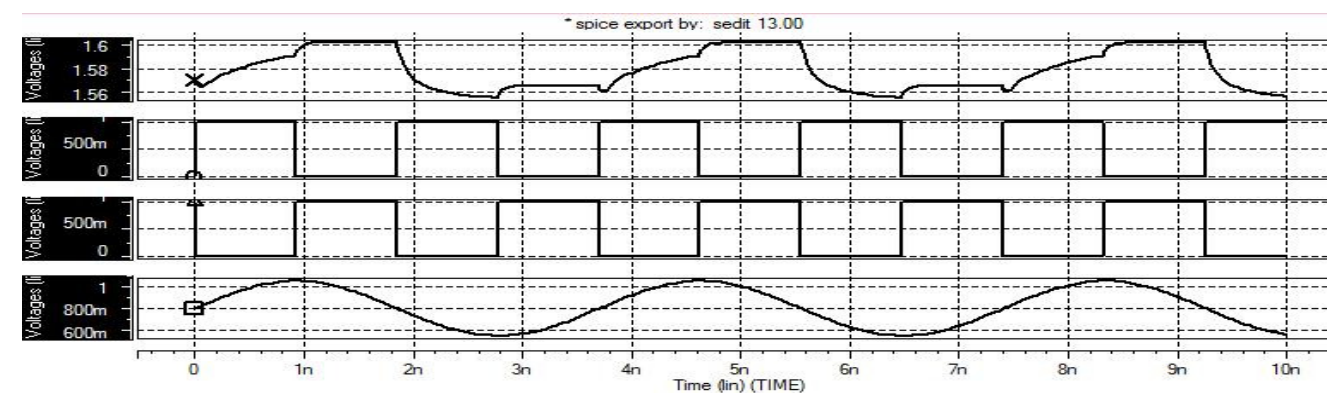

Figure 11. Output waveform for T/H using Transmission-gate sampling switch 
From the output waveform it is clear that $\mathrm{V}_{\text {out }}$ is linear in behaviour.

\subsubsection{Noise Analysis of Conventional T/H Circuit using Transmission-Gate}

Table 4. Noise results of conventional $\mathrm{T} / \mathrm{H}$ using Transmission-Gate

\begin{tabular}{|c|c|}
\hline $\begin{array}{l}\text { Total output noise } \\
\text { voltage }\end{array}$ & $\begin{array}{l}4.473 \mathrm{e}-019 \\
\mathrm{Sq} \mathrm{V} / \mathrm{Hz} \\
668.83807 \mathrm{p} \\
\mathrm{V} / \mathrm{Rt}(\mathrm{Hz})\end{array}$ \\
\hline $\begin{array}{l}\text { Transfer function } \\
\text { value (Vout/Vin) }\end{array}$ & $1.06742 n$ \\
\hline $\begin{array}{ll}\text { Equivalent } & \text { input } \\
\text { noise at Vin } & \\
\end{array}$ & $626.59340 \mathrm{~m}$ \\
\hline $\begin{array}{l}\text { Total equivalent } \\
\text { input noise voltage }\end{array}$ & $1.43876 \mathrm{~K} \mathrm{~V}$ \\
\hline
\end{tabular}

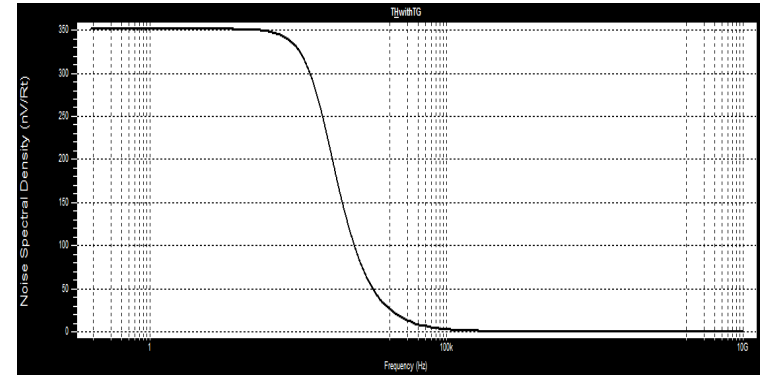

Figure 12. Output noise of conventional $\mathrm{T} / \mathrm{H}$ using Transmission-Gate

\subsection{Analysis of Pseudo-differential T/H circuit}

The $\mathrm{T} / \mathrm{H}$ circuit is implemented in a pseudo-differential fashion to suppress even-order nonlinearities as well as offset and common-mode noise. The biasing branch of the sourcefollower is, however, shared between the two half circuits to cancel the noise contribution of biasing devices.

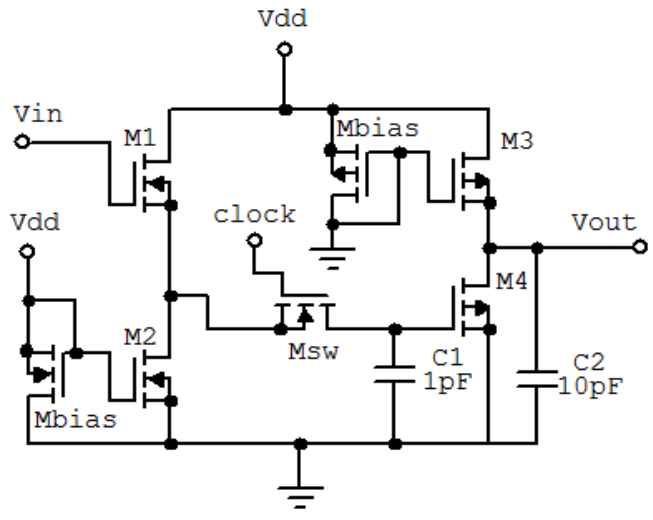

Figure 13. Pseudo-deferential T/H

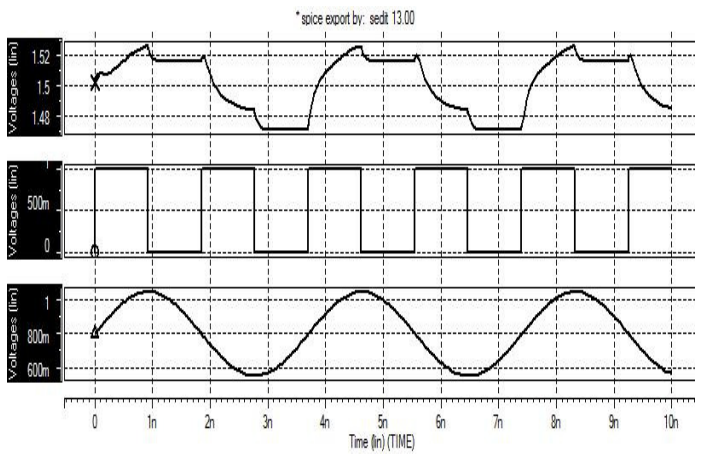

Figure 14. Output waveform for pseudodeferential $\mathrm{T} / \mathrm{H}$

Table 5. Hspice Simulation Result of Pseudo-Differential T/H

\begin{tabular}{|l|l|}
\hline Vout & $1.50 \mathrm{v}$ \\
\hline Average power consumption & $93.64 \mathrm{mw}$ \\
\hline Peak power over a cycle & $103.5 \mathrm{mw}$ \\
\hline Slew rate & $135 \mathrm{mv} / \mathrm{ns}$ \\
\hline Track time & $0.88 \mathrm{~ns}$ \\
\hline Hold time & $0.77 \mathrm{~ns}$ \\
\hline
\end{tabular}




\subsubsection{Noise Analysis of Pseudo-differential T/H circuit}

Table 6. Noise results of conventional $\mathrm{T} / \mathrm{H}$ using Transmission-Gate

\begin{tabular}{|l|l|}
\hline $\begin{array}{l}\text { Total output noise } \\
\text { voltage }\end{array}$ & $\begin{array}{l}5.674 \mathrm{e}-019 \\
\mathrm{Sq} \mathrm{V} / \mathrm{Hz} \\
=753.29254 \mathrm{p} \\
\mathrm{V} / \mathrm{Rt}(\mathrm{Hz})\end{array}$ \\
\hline $\begin{array}{l}\text { Transfer function } \\
\text { value (Vout/Vin) }\end{array}$ & $1.04183 \mathrm{n}$ \\
\hline $\begin{array}{l}\text { Equivalent input } \\
\text { noise at Vin }\end{array}$ & $723.05050 \mathrm{~m}$ \\
\hline $\begin{array}{l}\text { Total equivalent } \\
\text { input noise voltage }\end{array}$ & $1.63118 \mathrm{~K} \mathrm{~V}$ \\
\hline
\end{tabular}

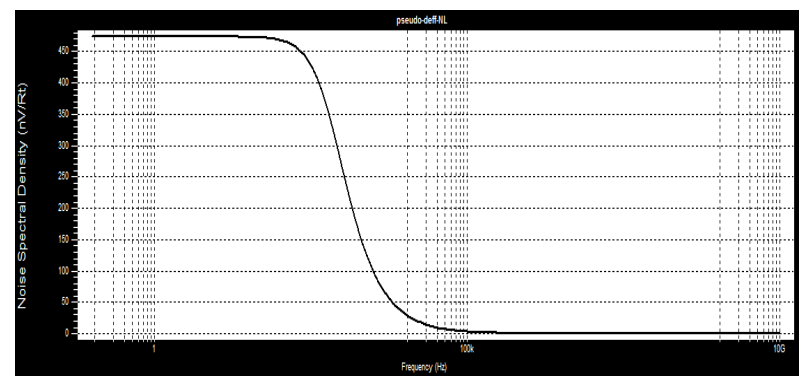

Figure 15. Output noise of pseudo-differential T/H

\subsection{Analysis of fully-differential $\mathrm{T} / \mathrm{H}$ circuit}

Figure 16. shows that input and output buffers of conventional Track-and-Hold circuit are modified in differential manner so that common mode noise could be suppressed. This architecture suppress the noise upto $60-70 \%$ as compared to conventional one but at the cost of power consumption and area overhead.

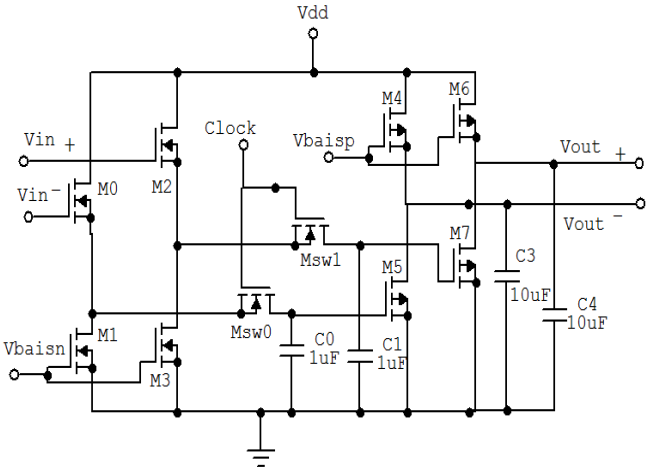

Figure 16. Fully-deferential T/H

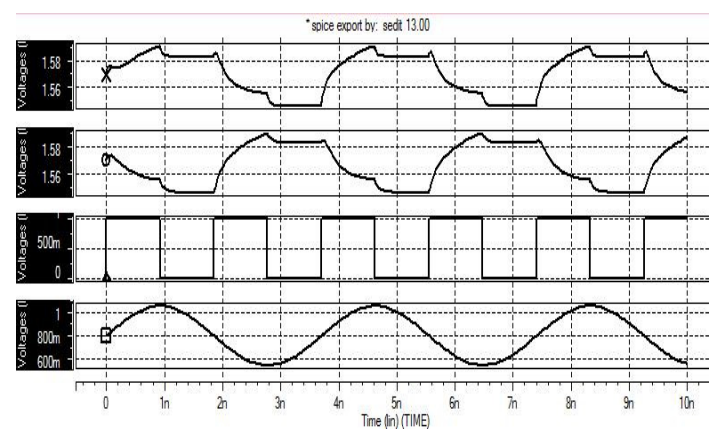

Figure 17. Output waveform of fullydeferential $\mathrm{T} / \mathrm{H}$

Table 7. Hspice simulation results of fully-differential T/H

\begin{tabular}{|l|l|}
\hline Vout & $1.56 \mathrm{v}$ \\
\hline Average power consumption & $162 \mathrm{mw}$ \\
\hline Peak power over a cycle & $182 \mathrm{mw}$ \\
\hline Slew rate & $181 \mathrm{mv} / \mathrm{ns}$ \\
\hline Track time & $0.92 \mathrm{~ns}$ \\
\hline Hold time & $0.81 \mathrm{~ns}$ \\
\hline
\end{tabular}




\subsubsection{Noise Analysis of fully-differential T/H circuit}

Table 8 . Noise results of fully differential

\begin{tabular}{|l|c|}
\hline \multicolumn{3}{|c|}{ T/H circuit } \\
Total output noise & $\begin{array}{l}2.981 \mathrm{e}-019 \quad \mathrm{Sq} \\
\text { V/Hz } \\
=546.01522 \mathrm{p} \\
\mathrm{V} / \mathrm{Rt}(\mathrm{Hz})\end{array}$ \\
\hline $\begin{array}{l}\text { Transfer function } \\
\text { value (Vout/Vin) }\end{array}$ & 0 \\
\hline $\begin{array}{l}\text { Equivalent input } \\
\text { noise at Vin }\end{array}$ & 0 \\
\hline $\begin{array}{l}\text { Total equivalent } \\
\text { input noise voltage }\end{array}$ & $0 \mathrm{~V}$ \\
\hline
\end{tabular}

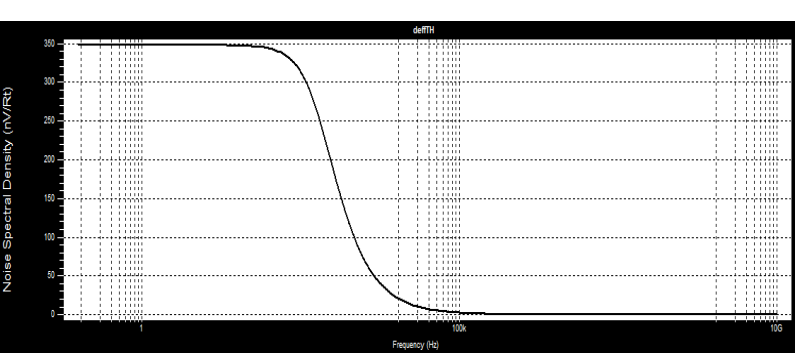

Figure 18. O/P Noise of fully-differential T/H

\subsection{Analysis of Two-Stage T/H using Conventional T/H Circuit}

In two-stage $\mathrm{T} / \mathrm{H}$ circuit, two conventional $\mathrm{T} / \mathrm{H}$ circuits are connected in cascade. The output of the first $\mathrm{T} / \mathrm{H}$ serves as the input to the next $\mathrm{T} / \mathrm{H}$. If the input voltage of a $\mathrm{T} / \mathrm{H}$ circuit is kept constant during its track phase, only one of charging or discharging is occurred in a track phase. In this case the output voltage of the $\mathrm{T} / \mathrm{H}$ circuit settles monotonously into the constant voltage from the beginning of the track phase and its hold time must be as long as possible. This reduction of the tracking time results in a low power consumption. In order to apply such a constant voltage to the $\mathrm{T} / \mathrm{H}$ circuit an additional small $\mathrm{T} / \mathrm{H}$ circuit is inserted in front of the original T/H circuit as shown in Figure 19. Inverting and non-inverting clocks are applied to the two switches, Msw0 and Msw1, respectively so that the two T/H circuits act reciprocally.

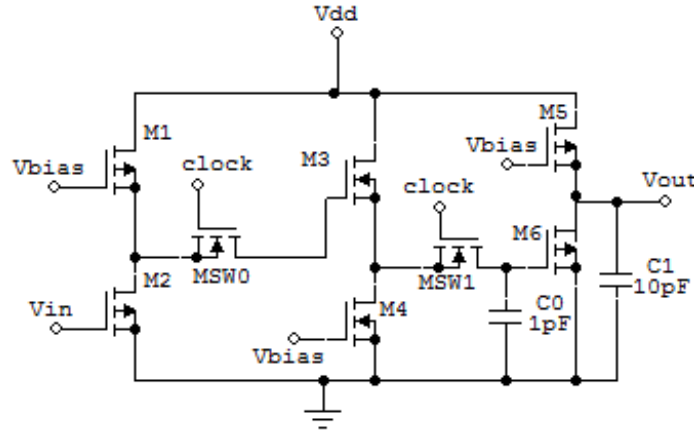

Figure 19. Two stage T/H circuit

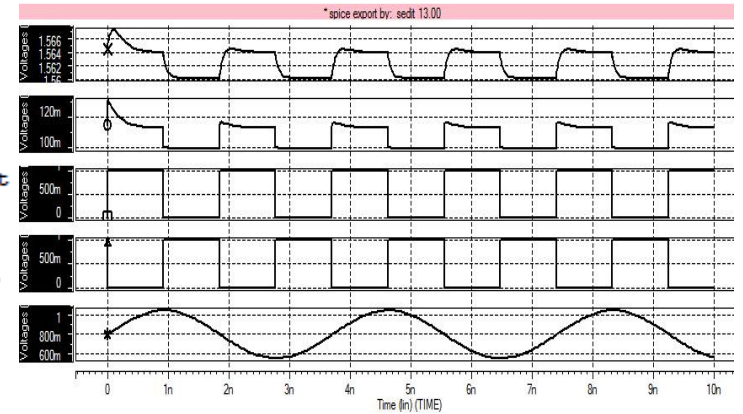

Figure 20. Output waveform of two stage T/H circuit

When the second $\mathrm{T} / \mathrm{H}$ circuit is in a track phase the first $\mathrm{T} / \mathrm{H}$ circuit is always in a hold phase whose output voltage is constant. The first $\mathrm{T} / \mathrm{H}$ circuit also charges and discharges its load capacitance during a track phase, however, it can operate very fast because its load capacitance is much smaller than that of the conventional $\mathrm{T} / \mathrm{H}$ circuit. The first $\mathrm{T} / \mathrm{H}$ circuit consumes very low power when the first T/H circuit and the conventional one have the same operation speed. The output voltage of the first stage is applied to the second $\mathrm{T} / \mathrm{H}$ circuit. When the second $\mathrm{T} / \mathrm{H}$ circuit is in the track phase, its input voltage is always constant because the first $\mathrm{T} / \mathrm{H}$ circuit is already in the hold phase. Therefore, its output voltage approaches to the final value directly and it's settling time decreases drastically [8]. 
Table 9. Hspice simulation results of two-stage T/H

\begin{tabular}{|l|l|}
\hline Vout & $1.59 \mathrm{v}$ \\
\hline Average power consumption & $64.30 \mathrm{mw}$ \\
\hline Peak power over a cycle & $69.80 \mathrm{mw}$ \\
\hline Slew rate & $37 \mathrm{mv} / \mathrm{ns}$ \\
\hline Track time & $.16 \mathrm{~ns}$ \\
\hline Hold time & $0.62 \mathrm{~ns}$ \\
\hline
\end{tabular}

HSpice simulation result (fig.20) shows that track-time in output waveform for two stages $\mathrm{T} / \mathrm{H}$ circuit is reduced drastically while the hold time in output waveform is increased.

\subsubsection{Noise Analysis of two-stage T/H circuit}

Table 10. Noise results of two-stage T/H

\begin{tabular}{|l|l|}
\hline $\begin{array}{l}\text { Total output noise } \\
\text { voltage }\end{array}$ & $\begin{array}{l}7.473 \mathrm{e}-020 \mathrm{Sq} \\
\mathrm{V} / \mathrm{Hz} \\
=273.36864 \mathrm{p} \\
\mathrm{V} / \mathrm{Rt}(\mathrm{Hz})\end{array}$ \\
\hline $\begin{array}{l}\text { Transfer function } \\
\text { value (Vout/Vin) }\end{array}$ & $115.94659 \mathrm{f}$ \\
\hline $\begin{array}{l}\text { Equivalent input } \\
\text { noise at Vin }\end{array}$ & $2.35771 \mathrm{~K}$ \\
\hline $\begin{array}{l}\text { Total equivalent } \\
\text { input noise voltage }\end{array}$ & $734.89198 \mathrm{~K} \mathrm{~V}$ \\
\hline
\end{tabular}

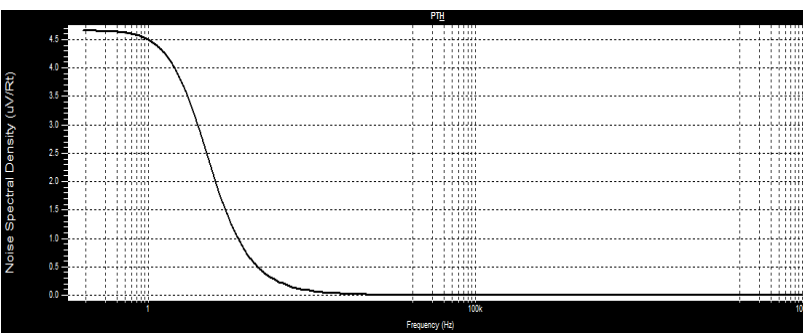

Figure 21. Output noise of two-stage T/H

\subsection{SLEW RATE LIMITATION OF SOURCE FOLLOWER T/H CIRCUIT}

When input signal is such that it demands an o/p response is faster than the specified value of slew rate (SR), non linear distortion will occur due to slew rate limitation.

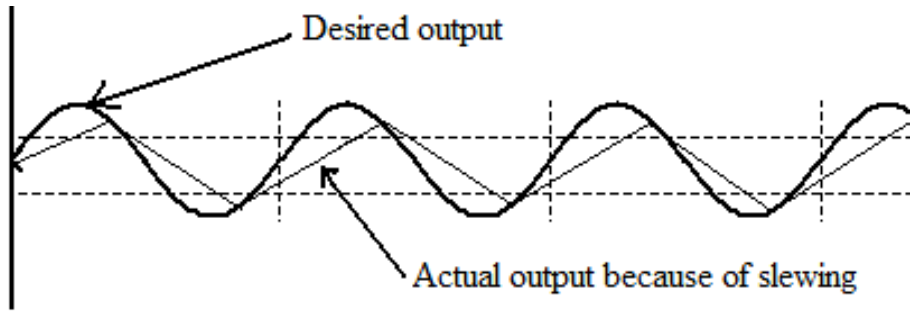

Figure 22. Slew rate distortion due to slewing

Slew rate limitation cause non linear distortion when $\mathrm{I} / \mathrm{P}$ is sinusoidal

$$
\begin{gathered}
\mathrm{V}_{\text {in }}=A_{\text {in }} \sin \left(\omega_{\text {in }} \mathrm{t}+\Phi\right) \\
\left(\mathrm{d} \mathrm{V}_{\text {in }} / \mathrm{dt}\right)_{\max }=A_{\text {in }} \omega_{\text {in }}
\end{gathered}
$$


Thus the maximum occurs at zero crossing of I/P sinusoidal. If $A_{\text {in }} \omega_{\text {in }}$ exceeds the slew rate of the input buffer the output waveform will be distorted. Output cannot keep up with this large rate of change of the input sinusoidal at its zero crossing \& hence source follower slews [7].

There is a specific frequency $\mathrm{f}_{\mathrm{M}}$ called the full-power bandwidth at which output voltage of the source follower begins to show distortion due to slew-rate limitation

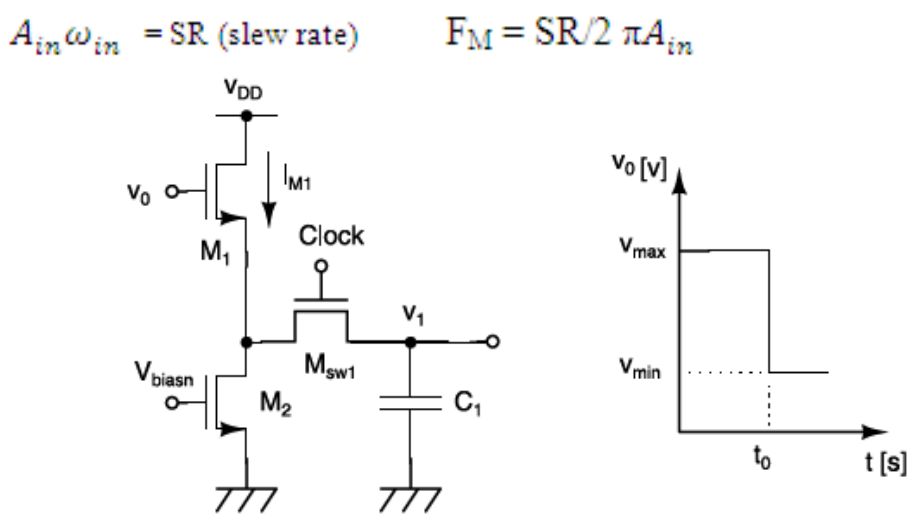

Figure 23. Single stage of source follower $\mathrm{T} / \mathrm{H}$

When the step voltage whose amplitude is larger than $\left(\mathrm{Vgs}-\mathrm{V}_{\mathrm{T}}\right)$ is applied to the single stage of source follower T/H circuit, $\mathrm{M}_{1}$ goes into the cut-off region at $\mathrm{t}=\mathrm{t}_{0}$. When $\mathrm{M} 1$ is cut off, its load capacitor is discharged by a constant current $\mathrm{I}_{\mathrm{M} 2}$. The slew rate is limited to $\mathrm{I}_{\mathrm{M} 2} / \mathrm{C}_{1}$.

The output voltage during the slewing can be represented by

$$
V_{1}=V_{\max }-V_{g s 1}-\frac{I_{M 2}}{C_{1}}
$$

Where $\mathrm{V}_{\mathrm{gs} 1}$ is the gate-to-source bias voltage of $\mathrm{M}_{1}$ On the assumption that an on-resistance of $\mathrm{M}_{\mathrm{sw} 1}$ is adequately small, this slewing continues as

$$
t_{s l e w}=\frac{c_{1}}{I_{M 2}}\left(V_{\max }-V_{\min }-V_{g s 1}+V_{T}\right)
$$

\subsection{COMPARISON OF POWER}

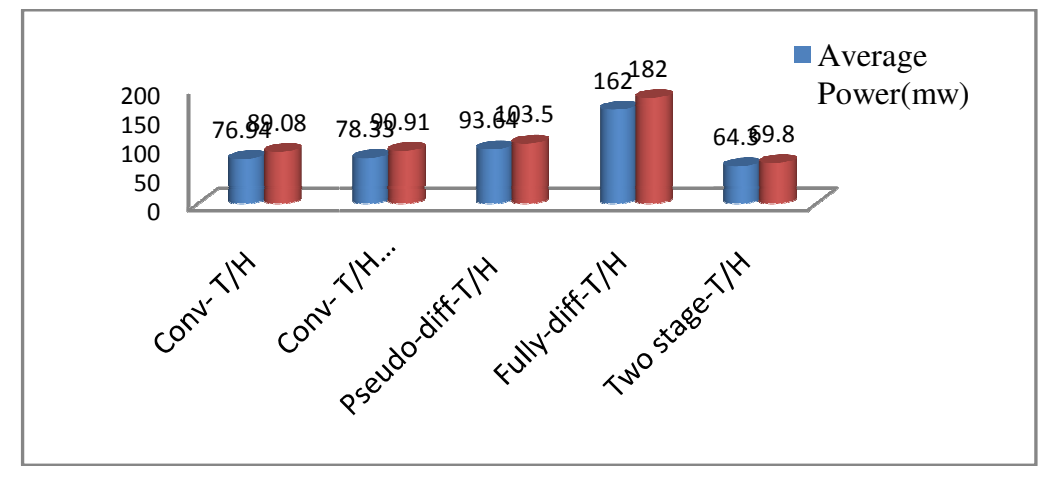

Figure 24. Comparison of power consumption

Figure 24. Shows that average power consumed by two stage Track-and-Hold circuit is minimum. 


\subsection{COMPARISON OF O/P NOISE}

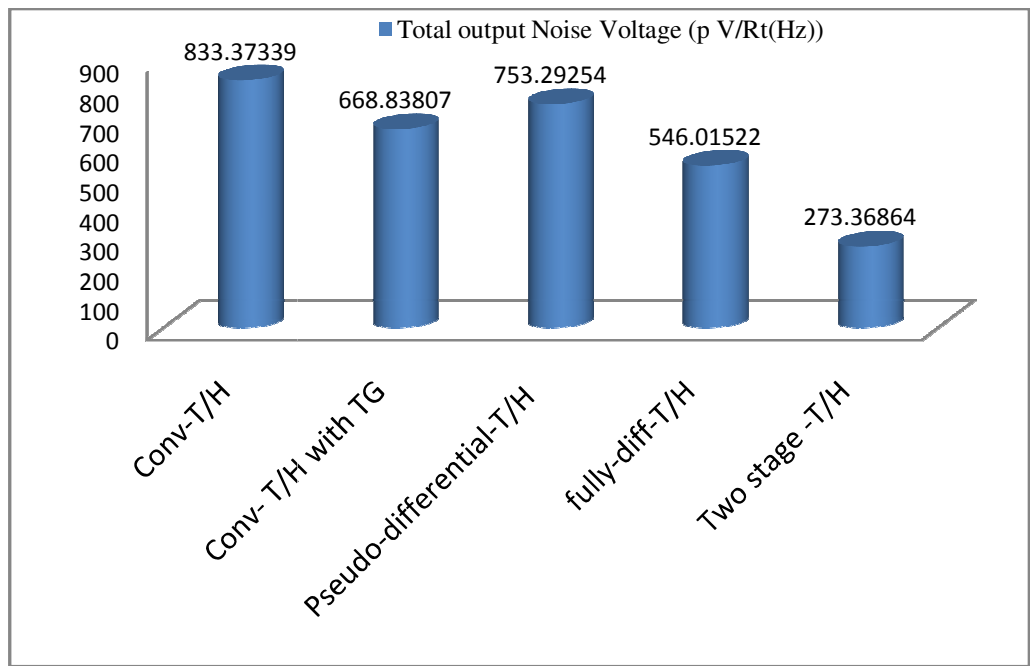

Figure 25. Comparison of $\mathrm{O} / \mathrm{P}$ noise voltage

Graph shows that the o/p noise voltage of two stage Track-and-Hold circuit is minimum.

\subsection{COMPARISON OF SLEW RATE}

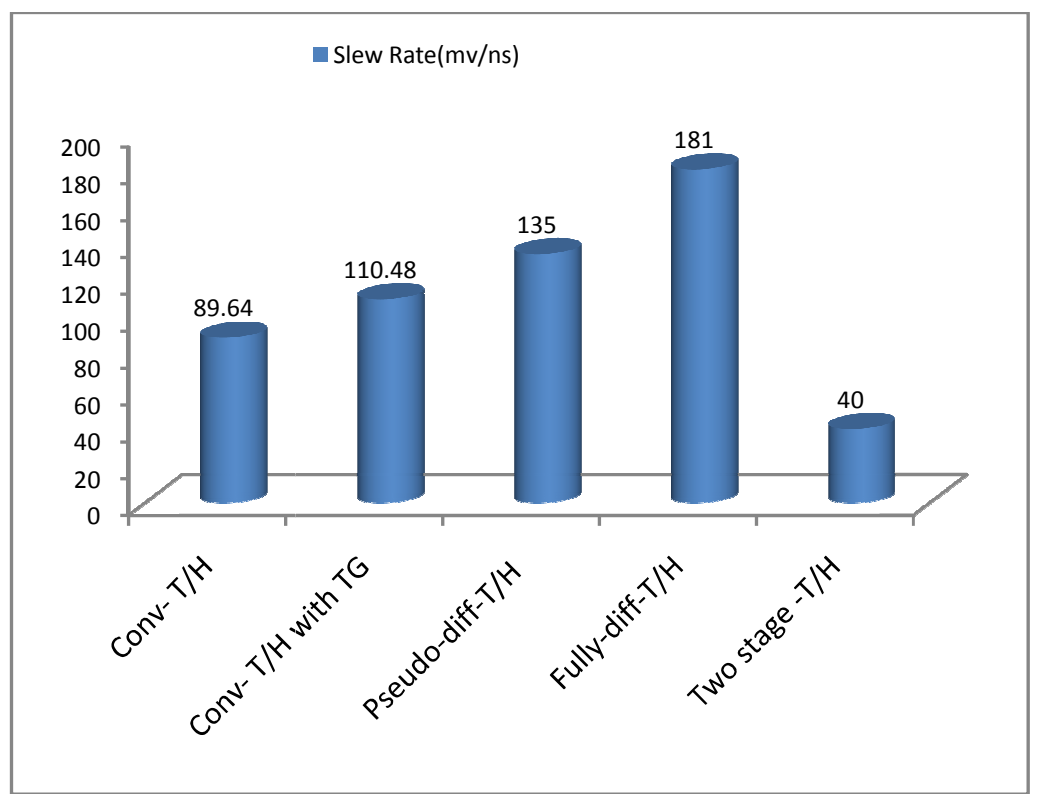

Figure 26. Comparison of Slew Rate

From figure 26. It is observeed that the slew rate of the fully-differential Track-and-Hold circuit is maximum. 


\section{Conclusions}

It is found that the on-resistance of transmission-gate-switch (NMOS and MOS-transistor connected in parallel) is much more linear. Later on, NMOS switches are replaced with transmission-gate-switch.

Two stage Track-and-Hold circuit shows $16.42 \%$ decrease in power consumption as compared to conventional Track-and-Hold circuit. Further, track time of two-stage T/H circuit is found to be .16(ns) which is minimum among all Track-and-Hold circuits. Hence two-stage structure is fastest among all designs. Fully differential Track-and-Hold circuit shows the highest slew rate (181 mv/ns) while two-stage T/H shows minimum slew (40 mv/ns). There is an $8.90 \%$ increase in $\mathrm{V}_{\text {out }}$ of two stage Track-and-hold circuit as compared to conventional Track-and-Hold circuit. Two-stage $\mathrm{T} / \mathrm{H}$ circuit shows $67.19 \%$ reduction in output noise voltage as compared to conventional Track-and-Hold circuit. Two Stage T/H Circuit based on source follower buffers mitigates the problem of power consumption, large track time and noise but at the cost of small value of slew rate. A unity-gain buffer is capable to achieve high slew rates in both positive and negative directions. By sensing the drain current of the common-drain device in an NMOS source follower, the extent of slewing could be achieved. So the future work of this dissertation would be implementation of high slew rate Track-and-Hold circuit by using an enhanced slew rate source follower buffers [7].

\section{ACKNOWLEDGEMENTS}

I express my heart-felt gratitude to Mr. Gagnesh Kumar, Assistant Professor, E\&C Department, NIT Hamirpur for his invaluable guidance and support throughout this work. His encouragement was very helpful for me to go ahead in this project.

I acknowledge with gratitude the technical and financial support from DIT, Ministry of Communications \& Information Technology, Govt. of India, New Delhi, through VLSI SMDPII Project at NIT Hamirpur HP.

\section{REFERENCES}

[1] S. H. Lewis and P. R. Gray, “A pipelined 5-Msample/s 9-bit analog-to digital converter,” IEEE J. Solid-State Circuits, vol. 22, pp. 954-961,Dec.87.

[2] A. M. Abo and P. R. Gray, "A 1.5-V, 10-bit, 14.3-MS/s CMOS pipeline analog-to-digital converter,” IEEE J. Solid-State Circuits, vol. 34, pp. 599-606, May 1999.

[3] S. Limotyrakis, S. D. Kulchycki, D. K. Su, and B. A. Wooley, “A 150- MS/s 8-b 71-mW CMOS time-interleaved ADC,” IEEE J. Solid-State Circuits, vol. 40, pp. 1057-1067, May 2005.

[4] M. Choi and A. A. Abidi, "A 6-b 1.3-Gsample/s A/D converter in 0.35- $\mu \mathrm{m}$ CMOS," IEEE J. Solid-State Circuits, vol. 36, pp. 1847-1858, Dec.2001. 
[5] W. Yang, D. Kelly, L. Mehr, M. T. Sayuk, and L. Singer, “A 3-V 340- mW 14-b 75-Msample/s CMOS ADC with 85-dB SFDR at Nyquist input,’IEEE J. Solid-State Circuits, vol. 36, pp. 1931-1936, Dec. 2001.

[6] A. Boni, A. Pierazzi, and C. Morandi, "A 10-b 185-MS/s track-and-hold in 0.35- $\mu$ m CMOS," IEEE J. Solid-State Circuits, vol. 36, pp. 195-203,Feb. 2001.

[7] An Enhanced Slew Rate Source Follower. John G. Kenney, Giri Rangan, Karthik Ramamurthy, and Gabor Temes, IEEE J. Solid-State Circuits, Vol. 36,pp.195-203,Feb. 2001

[8] Takahide SATO†a), Member, Isamu MATSUMOTO, Nonmember, Shigetaka TAKAGI, Member, and Nobuo FUJII, Fellow, Design of Low Power Track and Hold Circuit Based on Two Stage Structure, IEICE TRANS. ELECTRON., VOL.E91-C, NO.6 JUNE 2008

[9] W. Yu, S. Sen and B. H. Leung, "Distortion Analysis of MOS Track-and-Hold Sampling Mixers Using Time-Varying Volterra Series",IEEE Transactions on circuits and systems-II: Analog and Digital Signal Processing, vol. 46, No. 2, Feb.1999.

[10] Behzad Razavi, "Design of Analog CMOS Integrated Circuits", McGraw Hill Higher Education, 2001, ISBN 0-07-238032-2.

[11] D.A. Johns and K. Martin, Analog integrated circuit design, John Wiley \& Sons, 1997.

[12] Ruby van de Plassche, CMOS integrated analog to digital and digital to analog converters, Kluwer Academic Publishers, 2003.

[13] P. R. Gray, P. J. Hurst, H. Lewis, and R. G. Mayer, "Analysis and Design of Analog Integrated Circuits", 4th ed., Johnson Wiley and Sons, New York 2001

[14] F. Liu, S. Jia, Z. Lu, and L. Ji, "CMOS folding and interpolating A/D Converter with differential compensative T/H circuit," Proc.2003 IEEE Conference on Electron Devices andSolid-State Circuits, pp.453-456, 2003.

[15] T. Sato, S. Takagi, N. Fujii, Y. Hashimoto, K. Sakata, and H. Okada,“4GB/s track and hold circuit using parasitic capacitance canceler," Proc. European Solid-State Circuits Conference,pp.347-350, 2004.

[16] Mohammad Hekmat and Vikram Garg, "Design and Analysis of a Source-Follower Track-andHold Circuit" , EE315 (VLSI data conversion circuits) project report June 2006

[17] A.N. Karanicolas, “A 2.7-V 300-MS/s track-and-hold amplifier,” IEEE J. Solid-State Circuits, vol.32, pp.1961-1967, Dec. 1997.

[18] Tadeparthy P., Das M. “Techniques to improve linearity of CMOS Sample-and-Hold circuits for achieving $100 \mathrm{db}$ performance at 80Msps", IEEE Circuits and Systems, 2002

[19] Yasutaka Haga and Izzet Kale, "Class-AB Rail-to-Rail Cmos Buffer with Bulk-Driven Super Source Followers" ,applied DSP and VLSI research group school of Electronics and Computer Science University of Westminster, London, 978-1-4244-3896-9/09/@2009 IEEE

[20] A. J. López-Martin, J. Ramírez-Angulo, R. G. Carvajal, and L. Acosta,“Power-efficient Class AB CMOS Buffer”, IEE J. Electronic Letters, 2009, 45, (2), pp. 89-90. 
International Journal of VLSI design \& Communication Systems (VLSICS) Vol.2, No.1, March 2011

\section{Authors}

Manoj Kumar received B.Tech. degree from A.K.G Engineering College, Ghaziabad (U.P), India, in 2007 and M.Tech. degree from National Institute of Technology, Hamirpur (H.P), India, in July 2010. Since August 2010, he has been an Assistant Professor of Vidya College of Engineering, Meerut (U.P). His main interest lies in the field of low power analog integrated circuits, Digital VLSI Design, Microprocessor/Microcontrollers

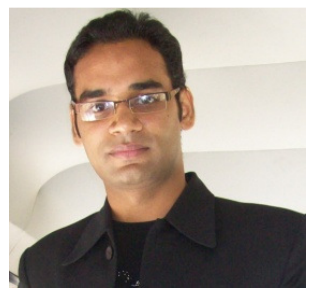

Gagnesh Kumar received B.E. degree from National Institute of Technology, India, in 2000 and M.Tech degree from Punjab University, Chandigarh, India, in 2003. He has been an Assistant Professor of National Institute of Technology, Hamirpur (H.P). His main interest lies in the field of Microelectronics, VLSI, Artificial intelligence, Neural networks.

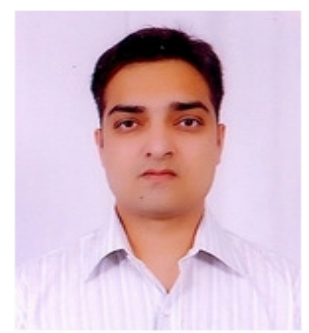

